\title{
Early diet in preterm babies and developmental status in infancy
}

\author{
A LUCAS, ${ }^{*} \mathrm{R}$ MORLEY, ${ }^{*} \mathrm{~T} \mathrm{~J}$ COLE, ${ }^{*} \mathrm{~S}$ M GORE, $\dagger \mathrm{J}$ A DAVIS, $\ddagger$ M F M BAMFORD, $\S$ \\ AND J F B DOSSETOR\|
}

${ }^{*}$ MRC Dunn Nutrition Unit, and $†$ Biostatistics Unit, Cambridge, and Departments of Paediatrics, $¥$ University of Cambridge, §Heath Road Hospital, Ipswich, and \|Queen Elizabeth Hospital, King's Lynn

SUMmARY Few data from randomised prospective studies address whether early diet influences later neurodevelopment in man. As part of a larger multicentre trial, 502 low birthweight infants were assigned randomly, for a median of 30 days, to receive a preterm formula or unfortified donor breast milk as sole diets or as supplements to their mothers' expressed milk. Surviving infants were assessed at nine months after their expected date of delivery without knowledge of their feeding regimen. The mean developmental quotient was 0.25 standard deviations lower in those fed donor breast milk rather than preterm formula. In infants fed their mother's expressed milk, however, the disadvantage of receiving banked milk compared with preterm formula as a supplement, was greater when the supplement was over half the total intake, and approached five points, representing 0.5 standard deviations for developmental quotient. Infants fed donor breast milk were at particular disadvantage following fetal growth retardation, with developmental quotients $5 \cdot 3$ points lower.

We suggest that the diet used for low birthweight babies over a brief, but perhaps critical, postnatal period has developmental consequences that persist into infancy; infants who are small for gestational age are especially vulnerable to suboptimal postnatal nutrition.

Whether early diet influences later development is a key question in infant nutrition that has stimulated numerous investigations in animals and man. Most animal studies have been in rats, whose young are very immature at birth. In such experiments both prenatal and early postnatal malnutrition may have significant neurological consequences including a serious loss of brain cells found at necropsy, ${ }^{12}$ a brain-weight deficit that usually remains after nutritional rehabilitation, ${ }^{3-5}$ and impaired performance in learning tasks and visual discrimination tests. ${ }^{6}$

In human infants who have died of severe malnutrition, the total number of brains cells has been found to be reduced by $15-20 \%$, and by $60 \%$ in those born weighing under $2000 \mathrm{~g},{ }^{7}$ which suggests that all low birthweight infants (whether or not they are small for gestational age) are especially vulnerable to poor postnatal nutrition. Human studies on early diet and later neurodevelopment, however, are difficult to interpret. Much work in humans concerns the consequences of malnutrition in developing countries, where poor diet is associated with medical and social problems that confound any analysis. Thus some workers report behavioural or intellectual benefits from dietary supplementaion following malnutrition in infancy, ${ }^{89}$ whereas others suggest that stimulation was essential for these benefits. ${ }^{10}$ Evidence indicating that early nutrition may have lasting neurodevelopmental effects has, however, come from many other sources. These include studies on malnutrition associated with disease (for instance, infantile hypertrophic pyloric stenosis, which has been associated with later deficits in attention and memory ${ }^{11}$ ) and with the effects of specific nutrient deficiencies (for example, iron $^{12}$ ).

Nevertheless it has been difficult to conduct controlled randomised trials to test the hypothesis that early diet is critical for later neurodevelopment in humans. We considered that the preterm infant, born during a phase of rapid brain growth, would be an important model for such a study; currently used 
diets differ greatly in composition and randomised dietary assignment is practical. Furthermore a conclusive outcome trial would have important implications for clinical management.

We have therefore conducted a prospective, randomised five centre trial of the effect of diet on long term neurodevelopment in infants weighing under $1850 \mathrm{~g}$ at birth. The cohort will be followed into adult life; the first formal follow up was 18 months after their expected date of delivery, but in three East Anglian centres we also examined surviving infants at nine months after their expected date of delivery. Our findings at nine months are reported here.

\section{Patients and methods}

All infants weighing less than $1850 \mathrm{~g}$ admitted to the neonatal units in Cambridge, Ipswich, or King's Lynn over the three year period 1982-4 were entered into this study. Babies were excluded only if they had a major congenital abnormality known to impair growth or development (for example, trisomy), or if they died before randomisation (within the first 48 hours). Approval was obtained for the study from the local ethics committee in each of the trial centres. An important aspect of this study is that after detailed explanation of the study to the guardian(s), consent for the infant to take part was never withheld, so that there was no selection bias in the cohort.

Each mother was asked whether or not she wished to provide expressed breast milk for her infant. If a mother chose not to provide her milk, the infant was randomly allocated either banked donor breast milk or preterm formula as the sole diet (trial 1). Infants whose mothers elected to provide breast milk were randomly allocated (trial 2) either banked donor breast milk or preterm formula as a supplement to be used when mothers were unable to provide sufficient milk to meet their infants' enteral feed volume requirements. The median intake of maternal milk in this 'supplement trial' was $53 \%$ of the infants' feed volume during the study. Randomisation, by permuted blocks of variable length, was stratified by centre and birth weight; infants whose birth weight was below $1200 \mathrm{~g}$ were randomised separately. Full details of the randomisation, feeding regimens, and preterm formula composition have been published elsewhere ${ }^{1.3}$ but briefly, the preterm formula contained $2 \mathrm{~g}$ protein, $0.335 \mathrm{MJ}(80 \mathrm{kcal})$, $35 \mathrm{mg}$ phosphorus, $70 \mathrm{mg}$ calcium, and $45 \mathrm{mg}$ sodium $100 \mathrm{ml}$. Before the start of the study in 1982 all infants in the three centres were fed on human milk (banked, or mothers" own, or a combination).

Extensive data were collected on obstetric, fetal, and neonatal factors. The Registrar General's classification was used to code social class ${ }^{14}$; birth rank is the infant's birth order in the living children of the family, infants from multiple births being assigned equal rank.

The assigned diet was discontinued at the time of discharge from the neonatal unit or when a weight of $2000 \mathrm{~g}$ had been attained. After discharge from the neonatal unit mothers fed their infants as they and their local advisers chose.

Children were invited for follow up examination nine months after their expected date of delivery. The median age at follow up was 40.4 weeks (lower quartile $39 \cdot 6$, upper quartile $41 \cdot 7$ ). Full history and physical examination were undertaken by RM in Cambridge and King's Lynn, and by MB in Ipswich.

Knobloch et al's developmental screening inventory was given to each child to assess five fields of behaviour: adaptive, gross motor, fine motor, language, and personal-social. ${ }^{15}$ For each field a quotient adjusting for prematurity was calculated as follows: observed maturational age divided by attained age from expected date of delivery multiplied by 100; an overall developmental quotient was calculated as the mean of the five scores for each subject. It should be emphasised that the assessment at this and subsequent periods was done with the assessor having no access to data on previous dietary assignment.

In addition to developmental testing, the infants were assessed neurologically by the same examiner with the method described by Amiel-Tison and Grenier. ${ }^{16}$ Infants were categorised as neurologically normal, equivocal, or impaired. The tests lay particular emphasis on abnormalities in tone in the diagnosis of neurological impairment. Although 18 month developmental data are not reported here, we have included the assessment of neurological impairment that was made at 18 months with the same tests.

Developmental scores for neurologically impaired infants can be a poor measure of their intellectual development, as many test items require manipulative skills appropriate for age. Results have therefore been analysed separately for infants diagnosed as being impaired at nine months. Statistical analysis was by Student's $t$ test; results are also shown as $95 \%$ confidence intervals. Tests for interaction were performed to determine whether the dietary effect on development differed significantly between contrasting subgroups (for example, boys compared with girls, or small compared with appropriate size for gestational age). The significance of this interaction was assessed by comparing the differences in dietary effect between two subgroups, again by Student's $t$ test. 
1572 Lucas, Morley, Cole, Gore, Davis, Bamford, and Dossetor

\section{Results}

Altogether 502 infants were enrolled in this study. The mothers of $343(68 \%)$ chose to provide their breast milk, those of $159(32 \%)$ elected not to do so. Table 1 shows the mortality before nine months after the expected date of delivery, and the demographic and clinical details of surviving infants in each group who were successfully followed up at this age. Fifty nine surviving children were not seen; seven had moved overseas, nine refused follow up, and 43 were either untraced or unable to keep their appointment (47 of these 59 were subsequently seen at 18 months, when $96 \%$ of survivors were seen).

There were no significant differences between feed groups in follow up rate, mean length of gestation, birth weight, size for gestational age, sex distribution, Apgar score at five minutes, the proportion of infants requiring mechanical ventilation for 24 hours or more. social class, mother's education, or the infant's birth rank (data for a selection of these factors are shown in table 1). The median number of days (lower and upper quartile) to discontinuation of the assigned diet for infants fed donor milk (as sole diet or supplement) were 31 ( 22 , 49 ), and the corresponding values for infants fed preterm formula were $28(19,40)$. There was no significant difference in the percentage of supplement received between infants fed formula or donor milk, $43.8 \%$ compared with $51 \cdot 3 \%$, respectively (SD 36\%).

The numbers of infants in each group diagnosed as neurologically normal, equivocal, or impaired are shown in table 2 . There are no significant differences in the incidence of neurological impairment.

Table 3 shows mean developmental scores for all five fields of development and for overall developmental quotient in the randomised comparisons. These data do not include scores for neurologically impaired infants, which are considered separately.

When the two trials were combined the infants

Table 1 Comparison of preterm infants randomly assigned to receive banked breast milk or preterm formula as sole diet or as supplements to their mothers' milk

\begin{tabular}{|c|c|c|c|c|}
\hline & \multicolumn{2}{|l|}{ As sole diet } & \multicolumn{2}{|c|}{ As supplement to their mothers milk } \\
\hline & $\begin{array}{l}\text { Banked breast } \\
\text { milk }\end{array}$ & $\begin{array}{l}\text { Preterm } \\
\text { formula }\end{array}$ & $\begin{array}{l}\text { Banked breast } \\
\text { milk }\end{array}$ & $\begin{array}{l}\text { Preterm } \\
\text { formula }\end{array}$ \\
\hline No randomised & 83 & 76 & 170 & 173 \\
\hline No who died before the age of 9 months* & 7 & 9 & 12 & 15 \\
\hline $\begin{array}{l}\text { No }(\%) \text { seen nine months after the } \\
\text { expected date of delivery }\end{array}$ & $66 / 76(87)$ & $56 / 67(84)$ & $140 / 158(89)$ & $138 / 158(87)$ \\
\hline $\begin{array}{l}\text { Characteristics of infants seen at nine months: } \\
\text { Mean (SD) gestational age (weeks) } \\
\text { Mean (SD) birth weight (g) } \\
\text { No (\%) weighing }<1200 \mathrm{~g} \text { at birth } \\
\text { No }(\%) \text { small for gestational age } \div \\
\text { No }(\%) \text { boys } \\
\text { No }(\%) \text { from social classes I. II or III non-manual } \\
\text { No (\%) ventilated }>1 \text { day } \\
\text { Median (quartiles) No of days to full feeds }\end{array}$ & $\begin{array}{l}31 \cdot 2(2 \cdot 8) \\
1392(298) \\
18(27) \\
24(36) \\
31(47) \\
14(21) \\
27(41) \\
6(5.8)\end{array}$ & $\begin{array}{l}30 \cdot 8(2 \cdot 8) \\
1364(300) \\
17(30) \\
20(36) \\
26(46) \\
14(25) \\
27(48) \\
9(6.16)\end{array}$ & $\begin{array}{l}30 \cdot 9(2 \cdot 7) \\
1385(297) \\
36(26) \\
37(26) \\
75(54) \\
49(35) \\
51(36) \\
6(5.9)\end{array}$ & $\begin{array}{l}30 \cdot 9(2 \cdot 4) \\
1386(275) \\
38(28) \\
49(36) \\
84(61) \\
54(39) \\
55(40) \\
8(6.10)\end{array}$ \\
\hline
\end{tabular}

${ }^{*}$ Fifteen of the 43 deaths occurred before enteral feeds had been started. $;$ birth weight less than 10th centile.

Table 2 Neurological status, at nine months and at 18 months after the expected date of delivery assessed without knowledge of the feeding regimen by the methods of Amiel-Tison and Grenier ${ }^{16}$

\begin{tabular}{|c|c|c|c|c|}
\hline & \multicolumn{2}{|l|}{ As sole diet } & \multicolumn{2}{|c|}{ As supplement to their mother's milk } \\
\hline & $\begin{array}{l}\text { Banked breast } \\
\text { milk }\end{array}$ & $\begin{array}{l}\text { Preterm } \\
\text { formula }\end{array}$ & $\begin{array}{l}\text { Banked breast } \\
\text { milk }\end{array}$ & $\begin{array}{l}\text { Preterm } \\
\text { formula }\end{array}$ \\
\hline $\begin{array}{l}\text { Total assessed for impairment } \\
\text { At nine months: }\end{array}$ & 66 & 56 & 140 & 138 \\
\hline Impaired & 4 & 8 & 7 & 12 \\
\hline Equivocal & 0 & 1 & 8 & 3 \\
\hline Total & 4 & 9 & 15 & 15 \\
\hline Impaired at 18 months & 4 & 7 & 11 & 10 \\
\hline
\end{tabular}


Table 3 Developmental scores at nine months after the expected date of delivery for infants born preterm who had been randomly assigned during the early weeks after birth to receive banked breast milk or preterm formula as: sole diets or supplements to mothers milk (trials 1 and 2 combined); as sole diets (trial 1); or as supplements to their mothers' milk (trial 2). Data include overall developmental quotient and scores for five individual fields of development, expressed as mean $(S D)$ with $95 \%$ confidence intervals for benefit from preterm formula

\begin{tabular}{|c|c|c|c|}
\hline & $\begin{array}{l}\text { Banked } \\
\text { breast milk }\end{array}$ & $\begin{array}{l}\text { Preterm } \\
\text { formula }\end{array}$ & $\begin{array}{l}\text { Difference-95\% } \\
\text { confidence interval }\end{array}$ \\
\hline \multicolumn{4}{|l|}{ Trials 1 and 2 combined: } \\
\hline No of infants & 195 & 174 & \\
\hline Overall developmental quotient & $97.9 \quad(9 \cdot 6)$ & $100.4(10 \cdot 7)$ & $0 \cdot 4$ to $4 \cdot 6^{* *}$ \\
\hline Adaptive & $101 \cdot 3(11 \cdot 1)$ & $104.0(11.6)$ & $0 \cdot 4$ to $5 \cdot 1^{* *}$ \\
\hline Gross motor & $99.9(17 \cdot 2)$ & $102 \cdot 3(17 \cdot 7)$ & -1.2 to 5.9 \\
\hline Fine motor & $96 \cdot 6(12 \cdot 2)$ & $99.2(13.5)$ & 0.0 to $5 \cdot 3^{*}$ \\
\hline Language & $93 \cdot 3(10 \cdot 0)$ & $95 \cdot 6(12 \cdot 4)$ & 0.0 to $4.6^{*}$ \\
\hline Personal-social & $98 \cdot 0(11 \cdot 4)$ & $100 \cdot 6(12 \cdot 6)$ & $0 \cdot 2$ to $5 \cdot 1^{*}$ \\
\hline \multicolumn{4}{|c|}{ Trial 1-Banked milk compared with preterm formula as sole diets: } \\
\hline No of infants & 62 & 48 & \\
\hline Overall developmental quotient & $97 \cdot 2 \quad(8 \cdot 5)$ & $98 \cdot 2(11 \cdot 0)$ & $-2 \cdot 7$ to $4 \cdot 8$ \\
\hline Adaptive & $99.5(10 \cdot 2)$ & $101.6(10.5)$ & -1.8 to 6.0 \\
\hline Gross motor & $98.9(16 \cdot 2)$ & $98.7(15 \cdot 2)$ & $-6 \cdot 2$ to $5 \cdot 6$ \\
\hline Fine motor & $95 \cdot 2(11 \cdot 0)$ & $97 \cdot 1(14 \cdot 5)$ & $-3 \cdot 1$ to $6 \cdot 8$ \\
\hline Language & $93.8(11.0)$ & $95 \cdot 2(15 \cdot 0)$ & $-3 \cdot 7$ to $6 \cdot 4$ \\
\hline Personal-social & $98 \cdot 5(8 \cdot 5)$ & $98 \cdot 5(11 \cdot 0)$ & $-4 \cdot 7$ to $4 \cdot 6$ \\
\hline \multicolumn{4}{|c|}{ Trial 2-Banked milk compared with preterm formula as supplements: } \\
\hline No of infants & 133 & 126 & \\
\hline Overall developmental quotient & $98 \cdot 2(10 \cdot 1)$ & $101 \cdot 2(10 \cdot 5)$ & $0 \cdot 5$ to $5 \cdot 6^{* *}$ \\
\hline Adaptive & $102 \cdot 1(11 \cdot 4)$ & $105.0(11.9)$ & $0 \cdot 0$ to $5 \cdot 7^{*}$ \\
\hline Gross motor & $100 \cdot 4(17 \cdot 7)$ & $103 \cdot 7(18 \cdot 4)$ & $-1 \cdot 2$ to $7 \cdot 7$ \\
\hline Fine motor & $97 \cdot 2(12 \cdot 8)$ & $100 \cdot 0(13 \cdot 1)$ & -0.3 to $6 \cdot 0$ \\
\hline Language & $93 \cdot 1 \quad(9 \cdot 6)$ & $95.8(11 \cdot 3)$ & $0 \cdot 1$ to $5 \cdot 3^{*}$ \\
\hline Personal-social & $97 \cdot 7(11 \cdot 6)$ & $101 \cdot 5(12 \cdot 2)$ & 0.8 to $6 \cdot 6^{* *}$ \\
\hline
\end{tabular}

Data from infants with neurological impairment are excluded here and reported separately in the text $\left({ }^{*}=\mathrm{p}<0 \cdot 05,{ }^{* *} \mathrm{p}<0 \cdot 025\right)$.

receiving preterm formula, either as sole diet or as supplement to their mothers' milk, had higher mean scores in all areas of development than those given donor milk as sole diet or supplement. Significant differences were seen in adaptive, fine motor, language, and personal-social areas, as well as in overall developmental quotient $(95 \%$ confidence interval (CI) for difference: 0.4 to $4 \cdot 6, p<0.02$ ).

None of the differences seen between those infants receiving either donor breast milk or preterm formula as sole diet (the smaller of the two trials) reached significance, though there was a trend in favour of the preterm formula. In the larger group of infants whose mothers chose to provide breast milk, however, those supplemented with formula had higher mean scores in all areas of development than those supplemented with donor milk. The differences were significant in adaptive, language, and personal-social scores, also in overall developmental quotient where a three point advantage $(95 \% \mathrm{CI} 0 \cdot 5$ to $5 \cdot 6, \mathrm{p}<0 \cdot 02)$ is seen for formula fed

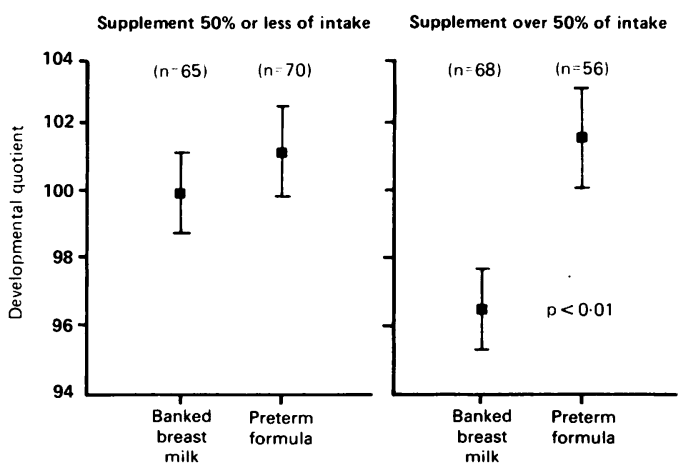

Fig 1 Mean developmental quotient at nine months after the expected date of delivery in preterm infants randomly assigned to receive either banked breast milk or preterm formula as supplements to their mothers' milk. Mean (SEM) values from babies for whom this supplement was $50 \%$ or less of intake are shown on the left, and for those for whom it was over $50 \%$ are shown on the right. 
infants. In this 'supplement trial', however, mothers provided varying proportions of their infants' milk volume requirements. When mothers provided most of the infants' feed volume, the nature of the randomly assigned supplement could not be expected to make a major difference to outcome. Thus any difference in outcome between donor milk and preterm formula given as supplements to maternal milk would be blunted. We planned in advance therefore to analyse the results separately for infants of mothers providing up to half of the enteral intake and those whose mothers provided more than half. As expected, developmental advantages for infants given preterm formula rather than banked milk were greater for those infants where the supplement comprised more than half of their milk volume requirement, with a 4.9 point advantage in developmental quotient for those receiving the formula rather than donor milk (101.4 (SD 10.5) compared with $96.5(9.9), \mathrm{p}<0.01$ ) (fig 1 and table 4).

Infants with neurological impairments $(n=31)$ were considered separately. For those fed donor milk compared with formula as sole diets or supplement the mean (SE) developmental quotients were $74.4(4.0)$ and $79.3(4.9)$, respectively.

A birthweight cut off of $1200 \mathrm{~g}$ was used for stratifying the randomisation, after we had established from local statistics that this figure was the watershed for prognosis. The developmental advantage for infants fed preterm formula, however, was equal above or below this value.

\section{SUBGROUP ANALYSES}

To investigate whether associations between diet and development were more evident in some subgroups, further analyses of the data were undertaken. For these analyses both trials were combined (preterm formula compared with banked milk as sole diets or supplements to mothers' milk). Subgroups investigated were: infants whose birth weights were appropriate for gestational age compared with those who were small for gestational age (less than the 10th centile), girls compared with boys, and those ventilated for less than 24 hours compared with those ventilated for 24 hours or longer.

The results are shown in fig 2 and table 5 .

Table 4 Mean (SD) developmental scores and $95 \%$ confidence intervals for the advantage of infants fed preterm formula rather than banked breast milk as supplements to their mothers' milk, in those infants in whom this supplement was more than half of the total intake

\begin{tabular}{|c|c|c|c|}
\hline & $\begin{array}{l}\text { Banked } \\
\text { breast milk } \\
(n=68)\end{array}$ & $\begin{array}{l}\text { Preterm } \\
\text { formula } \\
(n=56)\end{array}$ & $\begin{array}{l}95 \% \text { confidence } \\
\text { interval for advantage } \\
\text { of preterm formula }\end{array}$ \\
\hline $\begin{array}{l}\text { Overall developmental quotient } \\
\text { Individual subscales: }\end{array}$ & $96.5 \quad(9.9)$ & $101 \cdot 4(10 \cdot 5)$ & $1 \cdot 3$ to $8 \cdot 5^{* * *}$ \\
\hline Adaptive & $100 \cdot 2(10 \cdot 7)$ & $103 \cdot 7(10 \cdot 5)$ & -0.2 to 7.2 \\
\hline Gross motor & $98 \cdot 3(19 \cdot 0)$ & $103 \cdot 7(18 \cdot 0)$ & -1.6 to 12.4 \\
\hline Fine motor & $95 \cdot 2(13 \cdot 2)$ & $100 \cdot 3(13 \cdot 5)$ & 0.4 to $9.8^{*}$ \\
\hline Language & $92.9 \quad(9.1)$ & $97 \cdot 1(11 \cdot 2)$ & 0.6 to $7 \cdot 8^{* *}$ \\
\hline Personal-social & $96.5 \quad(9.9)$ & $101.4(11 \cdot 2)$ & $1 \cdot 7$ to $9 \cdot 3^{* * *}$ \\
\hline
\end{tabular}

${ }^{*}=\mathrm{p}<0 \cdot 05 ;{ }^{* *} \mathrm{p}=<0 \cdot 025 ;{ }^{* * *} \mathrm{p}=<0 \cdot 01$.

Table 5 Mean (SD) developmental scores and 95\% confidence interval for the advantage in small for gestational age infants fed preterm formula rather than banked breast milk

\begin{tabular}{llcc}
\hline & $\begin{array}{l}\text { Banked } \\
\text { breast milk } \\
(n=62)\end{array}$ & $\begin{array}{l}\text { Preterm } \\
\text { formula } \\
(n=68)\end{array}$ & $\begin{array}{c}95 \% \text { confidence } \\
\text { interval for benefit } \\
\text { of preterm formula }\end{array}$ \\
\hline $\begin{array}{l}\text { Overall developmental quotient } \\
\begin{array}{l}\text { Individual subscales: } \\
\text { Adaptive }\end{array}\end{array}$ & $94 \cdot 3(8 \cdot 7)$ & $99 \cdot 6(10 \cdot 7)$ & $2 \cdot 0$ to $8 \cdot 6^{* * *}$ \\
$\begin{array}{l}\text { Gross motor } \\
\text { Fine motor }\end{array}$ & $96 \cdot 7(11 \cdot 8)$ & $103 \cdot 8(12 \cdot 4)$ & $2 \cdot 9$ to $11 \cdot 1^{* * *}$ \\
$\begin{array}{l}\text { Language } \\
\text { Personal-social }\end{array}$ & $94 \cdot 9(17 \cdot 3)$ & $102 \cdot 5(18 \cdot 1)$ & $1 \cdot 4$ to $13 \cdot 5^{* *}$ \\
\end{tabular}

${ }^{*}=\mathrm{p}<0 \cdot 05:{ }^{* *} \mathrm{p}=<0 \cdot\left(025 ;{ }^{* * *} \mathrm{p}=<0 \cdot 01\right.$ 


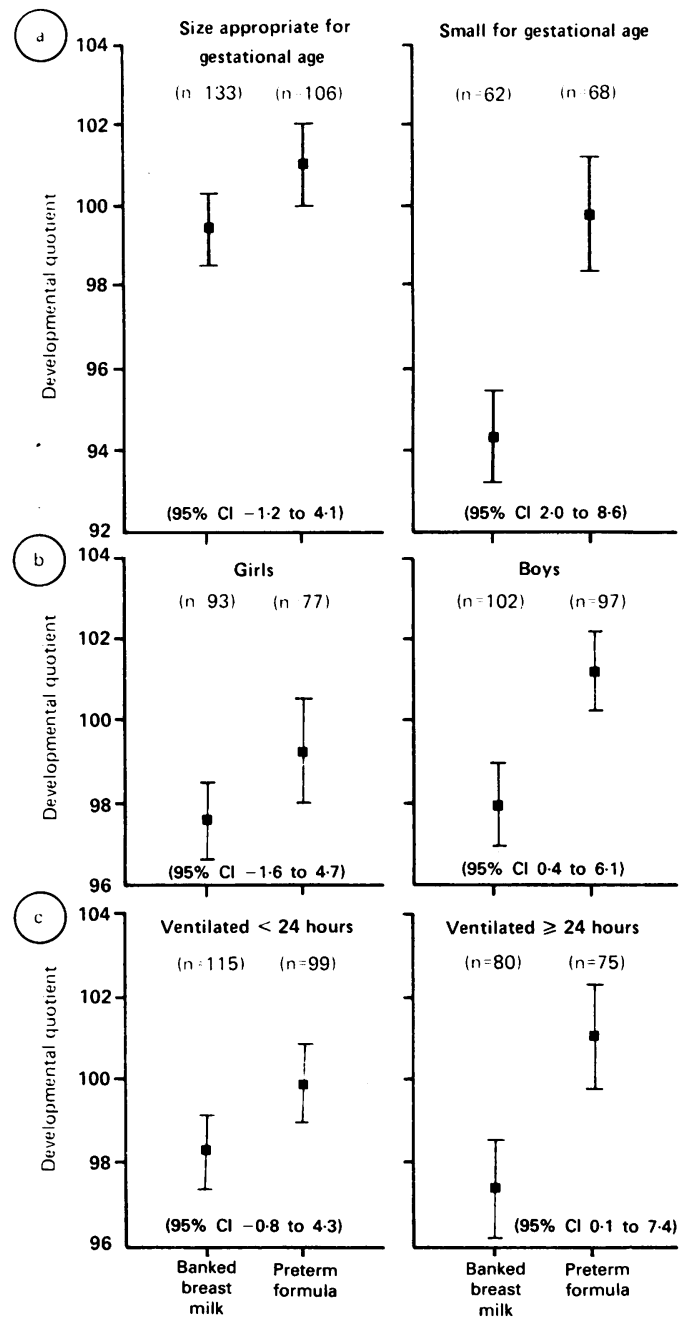

Fig 2 Mean developmental quotient at nine months after the expected date of delivery in preterm infants randomly assigned to receive either banked breast milk or preterm formula as sole diets or supplements to their mothers' milk. Values shown as mean (SEM) and $95 \%$ confidence intervals (CI) are given for the differences: (a) size appropriate for gestational age (left), and small for gestational age (right); (b) girls (left), and boys (right); and (c) ventilated $<24$ hours (left), and ventilated $\geqslant 24$ hours (right).

Birth weight appropriate for gestational age compared with small for gestational age The strongest association between diet and developmental quotient was seen in infants who were small for gestational age $(<10$ th centile) fig $2(a)$, table 5$)$. In this group there was a $5 \cdot 3$ point disadvantage $(\mathrm{p}<0.005)$ in overall mean developmental quotient for those fed banked milk rather than preterm formula. The disadvantage of donor milk in babies small for gestational age (trials 1 and 2 combined) is shown for each individual subscale in table 5; significant disadvantages were seen for adaptive, gross motor, fine motor, and personal-social scores, the greatest being a 7.6 point disadvantage on the gross motor scale $(p<0.02)$. There was significant interaction between these dietary effects and fetal growth retardation in the adaptive $(\mathrm{p}<0.01)$, gross motor $(p<0.05)$, and fine motor $(p<0.01)$ scores, and for overall developmental quotient $(p<0.05)$, showing that infants did indeed have a significantly greater developmental disadvantage on donor milk if they were small, rather than appropriate in size for gestational age.

Interestingly, infants receiving donor milk showed significant disadvantages in all fields of development except language after fetal growth retardation (table $5)$, whereas in infants of appropriate birth weight for gestational age the only significant disadvantage (not depicted) was seen on the language subscale (donor milk: $93.9(11.0)$ compared with preterm formula: $97.8(13.4))(\mathrm{p}<0.02)$. In this field there was also some evidence of interaction between diet and whether or not the infant's growth was retarded $(p=0 \cdot 09)$.

Boys compared with girls

Boys given preterm formula had a 3.3 point advantage in development quotient $(95 \%$ CI 0.4 to 6.1$)$, whereas girls had a smaller 1.7 point advantage (95\% CI 1.6 to 4.7 ) (fig 2(b)). A significant interaction between the dietary effects and sex of the infant was not found, however.

\section{Neonatal ventilation}

In infants ventilated for less than 24 hours there was no significant association between diet and developmental quotient, whereas those infants ventilated for 24 hours or more had a mean quotient which was 3.7 points higher if they received the formula rather than donor milk $(95 \% \mathrm{CI} 0 \cdot 1$ to $7 \cdot 4)$ (fig 2(c)), with a 6.2 point advantage in language development $(95 \%$ CI 2.4 to $10.0, p<0.002)$. In language development there was a significant interaction $(p<0.01)$ between the diet and whether the baby required mechanical ventilation for 24 hours or more.

\section{Discussion}

We have tested whether early diet influences neurodevelopment in man in a large, randomised, prospective trial of feeding in preterm infants. We 
found that the diet assigned during the early weeks after birth had a significant effect on developmental status nine months after the expected date of delivery. Infants fed a special cows' milk based preterm formula, had a significantly higher overall developmental quotient (when assessed by someone who was unaware of the randomisation) than those fed banked donor breast milk, when these diets were used alone and in combination with mothers' expressed milk. Though preterm formula feeding was associated with particular advantages in certain fields of development and subgroups of infants, in no specific instance was there any advantage for donor breast milk. These data have important biological implications and are pertinent to the long standing debate on whether unfortified mature human milk meets the nutritional requirements of premature babies. ${ }^{13}$

The developmental screening inventory of Knobloch et al that was used in this study consists of selected items from the Gesell developmental schedules. ${ }^{16}$ When Gesell developmental quotient and Stanford-Binet intelligence quotient at school age are compared, the Pearson correlation coefficient $(r)$ is 0.70 , rising to 0.84 after weighting for socioeconomic state and incidence of convulsive seizures. ${ }^{16}$ We expect that the correlation between mean development quotient and later mean intelligence quotient in randomised groups may be even better than correlations based on individuals. The longer term significance of our findings, however, is to be assessed at future follow up throughout childhood and beyond.

In trial 1, banked milk and preterm formula were assigned randomly as sole diets; in trial 2, they were given as supplements to the mothers' expressed breast milk (in volumes according to maternal success in providing sufficient milk to meet the infants' total feed volume requirement). Because in both trials the dietary assignment was random, demographic and clinical factors other than diet were equally represented between the two groups. Moreover, the combination of trials 1 and 2 was a balanced addition so that banked milk (as sole diet or supplement) compared with preterm formula (as sole diet or supplement) was still a randomised comparison.

We suggest that the observed significant differences in developmental scores between randomised diet groups are biologically important. Unlike intelligence quotient, the overall standard deviation for developmental quotient at nine months was only 10 points. In the whole cohort the overall disadvantage in developmental quotient on donor milk was $0.25 \mathrm{SD}$ and in several major subgroups (see below) this disadvantage was 5 to 8 points $(>0.5 \mathrm{SD})$.
Although other factors (such as very low gestational age or severe respiratory disease) are associated with larger differences in developmental status at this age, diet is one of the few potential influences on development that can be manipulated in clinical practice.

Given that donor breast milk conferred a later developmental disadvantage overall, it was surprising that no significant differences were found in the comparison of banked donor breast milk or preterm formula as sole diets (trial 1). This was the smaller of the two trials, however, and the trend was generally towards a reduced developmental quotient on donor milk. The randomised comparison between donor milk and preterm formula as supplement to mother's milk, based on a much larger sample, showed a significant developmental disadvantage for the infants fed on donor breast milk. In infants whose mothers provided their own milk, the developmental disadvantage for those receiving donor milk rather than preterm formula as a supplement was greater when the intake of supplement was more than half the feed volume requirements. This 'dose response' association further supports the evidence for an early dietary effect on development.

In addition to effects of diet on overall developmental quotient, the randomised groups (trials 1 plus 2) differed significantly in performance on four of the five individual subscales (adaptive, fine motor, language, and personal-social skills) but not in gross motor skills. The standard deviation on the gross motor score, however, was large (table 3), suggesting that preterm infants are selectively damaged in this respect, and a large population would have been required to detect a diet related difference in this subscale. Nevertheless, gross motor scores were significantly influenced by diet in infants born with retarded growth.

Prenatal and neonatal malnutrition have each been shown to be associated with a $15 \%$ reduction in the total number of brain cells in rats; yet when 'doubly deprived', with both prenatal and postnatal malnutrition, they suffered a $60 \%$ reduction in the total number of brain cells by the time of weaning. ${ }^{17}$ Though such data have uncertain relevance to man, we speculate that the infants in this study who were small for gestational age could be regarded as doubly deprived if, after intrauterine growth retardation, they were then fed an 'unfortified' diet such as banked breast milk (as a sole diet or supplement to maternal milk). Our previous studies $^{13}$ have indicated that human milk did not support intrauterine rates of somatic or head growth during the neonatal period, even in infants of normal birth weight, and certainly did not provide 
adequate nutrition for catch up growth in most of the infants born after growth had been retarded.

The significant interaction between diet and fetal growth retardation for developmental outcome indicates that infants in whom growth is retarded are especially vulnerable to postnatal undernutrition. Preterm formula fed infants had similar developmental quotients whether they were small or of appropriate size for gestational age, whereas infants fed donor milk were at a significant disadvantage if they were in the small for gestational age subgroup (fig 2(a)). Thus our data indicate that even with modern neonatal care, with emphasis on providing early nutrition, some available dietary regimens (especially when fed to neonates who are small for gestational age) may not permit achievement of full developmental potential in infancy.

Smart points out that in animal studies on undernutrition the effects on subsequent growth and behaviour are generally more pronounced in males than in females. ${ }^{18}$ Interestingly, we showed a greater dietary association with development in male children. Furthermore, sick infants who were ventilated for more than 24 hours showed a greater disadvantage on donor breast milk than those receiving minimal or no ventilatory assistance. For these differential effects on development to have more than speculative importance it would be necessary to show significant interactions between diet and sex, or diet and ventilation. We identified a highly significant interaction between diet and ventilation for language development (sick ventilated infants on donor milk showed a $6 \cdot 2$ point disadvantage). For overall developmental quotient, however, significant interactions with diet were not identified for either sex or ventilation, though to exclude such effects would have required a much larger number. Nevertheless, the consistency of the data with those in animals, together with the more convincing findings in infants whose growth was retarded, supports the view that it is the 'vulnerable' male infant who is prenatally malnourished, or sick, who is most severely disadvantaged if fed on an 'unfortified' diet.

Our multicentre study should be viewed as a group of 'management trials'. They were designed to answer the question: does the diet chosen for a preterm infant in the neonatal unit influence long term outcome? No attempt has been made to influence dietary management in the time period between discharge from the neonatal unit and the follow up examination. As the groups were assigned randomly, differences in feeding practice in this intervening period should not have occurred unless part of the effect of the initial diet was to induce some persistent change influencing the way the baby was subsequently fed.

Viewed solely as a management trial our study should not be expected to provide an explanation for any benefit in outcome that emerged. We have included a number of physiological and behavioural studies within these trials and our future analyses may shed light on the mechanisms responsible for observed outcomes. It seems plausible, however, that the developmental effects observed were a direct consequence of early nutrition, perhaps relating to an important dietary influence on early head, and therefore brain, growth. ${ }^{13} 19$ The explanation might, however, have been entirely different; for instance, the faster growth rate ${ }^{13}$ and hence earlier discharge home in preterm formula fed infants could have influenced the mother's behaviour towards the child, with consequent effects on development. It should be emphasised that donor milk and preterm formula differ both in nutrient and non-nutrient contents; an overall advantage for preterm formula may represent the sum of both benefits and disadvantages. Whether breast milk would confer a significant benefit over preterm formula if fortified to the same nutrient content is an important question requiring a further outcome trial. Regardless of the mechanism, it was surprising that a brief period of dietary manipulation (median 30 days) could have such prolonged consequences. It is unlikely that a comparable period of suboptimal nutrition in later childhood would have any lasting clinical significance. We suggest that the weeks immediately after birth constitute a 'critical period' for nutritional management.

The effects of early diet on later development shown in these infants have important implications for the dietary management of low birthweight infants, and bear on the more general issue of whether early diet has persistent neurodevelopmental consequences in man. Clearly future planned follow up of this cohort will permit us to examine the significance of our observations in terms of later performance.

We thank Dr R G Whitehead for help and encouragement, the staff of the special care baby units at Cambridge. Ipswich, and King's Lynn for their assistance and cooperation, and Farley Health Products for the manufacture of the preterm formula and financial and technical assistance.

\footnotetext{
References

1 Smart JL, Dobbing J, Adlard BPF, et al. Vulnerability of developing brain: relative effects of growth restriction during the fetal and suckling periods on behaviour and brain composition of adult rats. $J$ Nutr 1973;103:1327-38.
} 


\section{Lucas, Morley, Cole, Gore, Davis, Bamford, and Dossetor}

2 Stewart CA. Weights of various parts of the brain in normal and underfed albino rats at different ages. J Comp Neurol 1918;29: 511-28.

3 Siassi F, Siassi B. Differential effects of protein-calorie restriction and subsequent repletion on neuronal and nonneuronal components of cerebral cortex in newborn rats. J Nutr 1973;103: 1625-33.

4 Widdowson EM, McCance RA. Some effects of accelerating growth. I. General somatic development. Proc $R$ Soc Lond 1960;152:188-206.

5 Bedi KS, Thomas YM, Davies CA, Dobbing J. Synapse-toneuron ratios of the frontal and cerebellar cortex of 30-day-old and adult rats undernourished during early postnatal life. J Comp Neurol 1980;193:49-56.

6 Smart JL. Early life malnutrition and later learning ability: a critical analysis. In: Oliverio A, ed. Genetics, environment and intelligence. Amsterdam: Elsevier, 1977:215-35.

7 Winick M. Malnutrition and brain development. Oxford: Oxford University Press, 1976:115.

${ }^{8}$ Chavez A. Martinez C. Neurological maturation and performance on mental tests. Quoted in: Early nutrition and later achievement. London: Academic Press, 1987:138-9.

${ }^{9}$ Freeman HE, Klein RE, Townsend JW, et al. Nutrition and cognitive development among rural Guatemalan children. $A m \mathbf{J}$ Public Health 1980;70:1277-85.

10 Sinisterra L. Studies on poverts, human growth and development: the Cali experience. In: Dobbing J, ed. Early nutrition and later development. London: Academic Press, 1987:208-33.

11 Klein PS, Forbes GB, Nadar PR. Effects of starvation in infancy (pyloric stenosis) on subsequent learning abilities. $J$ Pediatr 1975;87:8-15.
12 Ankett MA, Parks YA, Scott PH, Wharton BA. Treatment with iron increases weight gain and psychomotor development. Arch Dis Child 1986;61:849-57.

13 Lucas A, Gore SM, Cole TJ, et al. Multicentre trial on feeding low birthweight infants: effects of diet on early growth. Arch Dis Child 1984;59:722-30.

14 Office of Population Censuses and Surveys. Classification of occupations 1980. London: HMSO, 1980.

15 Knobloch H, Pasamanick B. Sherard ES. A developmental screening inventory for infants. Pediatrics 1966;38:1095-108.

16 Ameil-Tison C, Grenier G. Neurological assessment during the first year of life. Oxford: Oxford University Press, 1986.

17 Minkowski A, Roux J-M, Tordet-Caridroit C. Pathophysiologic changes in intrauterine malnutrition. In: Winick $M$, ed. Nutrition and fetal development. Vol 2. New York: John Wiley, 1974:45-55.

18 Smart JL. Undernutrition, learning and memory: review of experimental studies. In: Taylor TG, Jenkins NK, eds. Proceedings of XIII International Congress of Nutrition. London: Libbey, 1986:74-8.

19 Cooke RWI, Lucas A, Yudkin PLN, Pryse-Davies J. Head circumference as an index of brain weight in the fetus and newborn. Early Hum Dev 1977;1:145-9.

Correspondence to Dr A Lucas, Dunn Nutritional Laboratory, Downham's Lane, Milton Road, Cambridge CB4 1XJ.

Accepted 1 June 1989 